\title{
OBSERVATION OF WILDFIRE SMOKE TRANSPORT AND PBL VARIATION DURING SUMMER 2018 LISTOS CAMPAIGN IN NEW YORK CITY
}

\author{
Yonghua Wu ${ }^{1,2^{*}}$, Kaihui Zhao ${ }^{3}$, Jianping Huang ${ }^{4}$, Dingdong Li ${ }^{1}$, Mark Arend ${ }^{1,2}$, Barry Gross ${ }^{1,2}$, \\ Fred Moshary ${ }^{1,2}$ \\ ${ }^{1}$ the City College of New York, NY, NY 10031, USA. *Email: yhwu@ccny.cuny.edu \\ ${ }^{2}$ NOAA - Cooperative Science Center for Earth System Sciences and Remote Sensing Technologies \\ ${ }^{3}$ School of Environment and Energy, South China University of Technology, Guangzhou 510006, China \\ ${ }^{4}$ NOAA-NCEP Environmental Modeling Center and IM System Group Inc., College Park, MD 20740, USA
}

\begin{abstract}
Air pollution associated with wildfire smoke transport and heat wave in summer pose serious public health concerns in the populated New York City (NYC) area. In this study, we present a synergistic lidar, ceilometer and in-situ observation for wildfire smoke transport and planetaryboundary-layer (PBL) variation in the NYC urban and coastal area during the summer 2018 Long Island Sound Tropospheric Ozone $\left(\mathrm{O}_{3}\right)$ Study (LISTOS). A dense smoke plume and mixing into PBL on August 15-17, 2018 was analyzed while the coincident enhancement of $\mathrm{PM}_{2.5}, \mathrm{CO}$ and $\mathrm{O}_{3}$ exceedance of NAAQS was demonstrated from both the observation and model. In addition, we show the temporal-spatial variation and difference of the PBL-height (PBLH) in the NYC urban and its coastal vicinity. We further evaluate the NAMCMAQ model forecast of $\mathrm{O}_{3}, \mathrm{PM}_{2.5}$ and PBLH with the ground observations.
\end{abstract}

\section{INTRODUCTION}

Air pollution episodes frequently occur in summer in NYC area, particularly $\mathrm{O}_{3}$ exceedance of national ambient air quality standard (NAAQS) in the urban and downwind coastal area of Long Island Sound (LIS) [1]. Extensive anthropogenic emissions, photochemical formation and urban heat island (UHI) magnify the air pollution impacts. In addition, long-range transport of wildfire smoke from northwest US and Canada can interact with PBL and affect the local air quality in $\mathrm{NYC} \mathrm{[2].} \mathrm{LIS} \mathrm{area} \mathrm{is} \mathrm{subject} \mathrm{to} \mathrm{high-levels} \mathrm{of} \mathrm{O}_{3}$ in the summer associated with the urban pollution transport and metrological conditions (i.e. shallow, stable marine PBL and sea breeze) [1,3]. To understand $\mathrm{O}_{3}$ episodes, wildfire smoke transport effects, and assess model forecast, it is necessary to make comprehensive and simultaneous observation of time-height distribution of aerosols, $\mathrm{O}_{3}$, and PBL in the NYC urban, coastal and marine region.

This abstract presents an integrated observation of elevated aerosol plumes, $\mathrm{PBLH}$, ground $\mathrm{PM}_{2.5}$, $\mathrm{O}_{3}$ and its precursors in summer 2018 LISTOS campaign. The observations include a multiwavelength elastic-Raman lidar, two ceilometers, a wind lidar and a microwave profiler to characterize diurnal vertical distribution and variation of aerosols and PBL. In particular, three-day shipborne measurements for the PBLH, VOCs, $\mathrm{O}_{3}$ and meteorological parameters are made in the LIS; and a coastal site facilitated with a ceilometer and $\mathrm{O}_{3}$ monitor was operated from July 27 to Sep.18, 2018. With the measurements, an initial comparison to the NOAA NAM-CMAQ model forecast is evaluated [4].

\section{METHODOLOGY}

At CCNY-campus, a suite of ground-based remote sensing instruments is deployed on a building roof, which include a 3-wavelength elastic-Raman lidar, a ceilometer, a microwave radiometer and a CIMEL sun/sky radiometer (part of NASA AERONET). Three elastic-scattering and two Raman-scattering returns by nitrogen and water vapor molecules excited by $355-\mathrm{nm}$ laser output are collected by a receiver telescope [5]. Two ceilometers (Vaisala CL-51 and CL-31) make automatic 24-hr/7-day observation at CCNY and a coastal site, respectively. We develop a qualityassurance (QA) method to optimize PBLH determination from raw aerosol-layer product. With the co-located sunphotometer-measured aerosol optical depth (AOD), aerosol extinction profiles and lidar-ratios are constrained in the lidar Fernald inversion [6]. In addition, the New York State Department of Environment Conservation 
(NYSDEC) samples $\mathrm{O}_{3}, \mathrm{NO}_{\mathrm{x}}, \mathrm{PM}_{2.5}$ and its speciation in the NYC area [7]. Figure 1 shows ground-based sites used in this study.

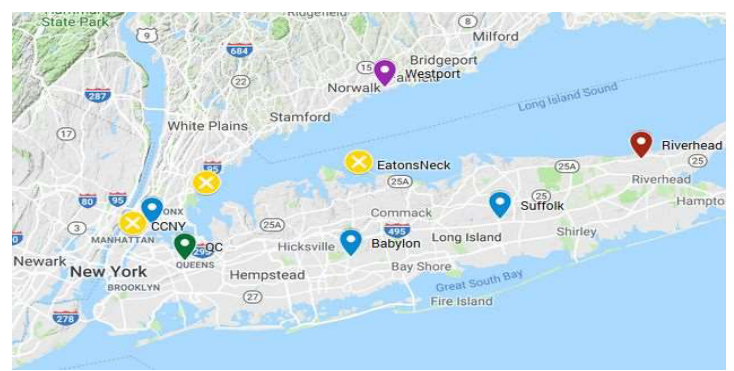

Fig.1 Ground-site location (yellow ' $\mathrm{x}$ ' set by CCNY)

\section{RESULTS and DISCUSSION}

\subsection{Smoke plumes on Aug.16, 2018}

Figure 2 (a) shows the multi-layer aloft plumes at $1.5 \sim 5 \mathrm{~km}$ altitude observed by CCNY-lidar on Aug. 16, 2018. Along with the PBLH growing and plume dispersion, the elevated plumes gradually mix into the PBL after 13:00 local time. The attenuated color-ratio in Fig.2 (b) can help discriminated the smoke from the scattered low clouds (large color-ratio at 15:30-18:00). The aerosol extinction coefficients in the aloft layer were larger than the ones in the PBL before 15:00 in Fig.2(c). According to the lidar-derived extinction profiles, the aloft-layers contribute $70 \%$ to the column AOD. In addition, Fig. 1(d) shows the wildfire sources (red + ) and smoke area (yellow) from the NOAA-HMS product, and the air backward trajectories (48hr long) with the end point at CCNY from the NOAA-HYSPLIT model. The results indicate that the main wildfire sources were located in the western Canada and northwest US, and the wildfire smoke was moving east across a large section of the northern US and southern Canada. Furthermore, we plot the vertical integrated smoke by the NOAA-HRRR smoke model on in Fig.2 (d); the dense smoke in the northwest US/Canada and transport to the northeast US can be clearly seen.

Figure 3 gives the temporal variation of ground $\mathrm{PM}_{2.5}, \mathrm{O}_{3}$ and carbon monoxide (CO) during Aug.12-31, 2018. Two significant enhancement processes of $\mathrm{PM}_{2.5}$ are shown on Aug.15-17 (prevailing northwest wind) and 27-29 (southwest wind), respectively. The hourly $\mathrm{O}_{3}$ are in exceedance of NAAQS (70-ppb). As a smoke indicator, the $\mathrm{CO}$ indicate concurrent increase. Such air pollution event associated with the wildfire smoke transport might be identified as the "exceptional event" according to EPA guidance. 20180816 CCNY-lidar attenuated backscatter (a.u.) at 1064-nm
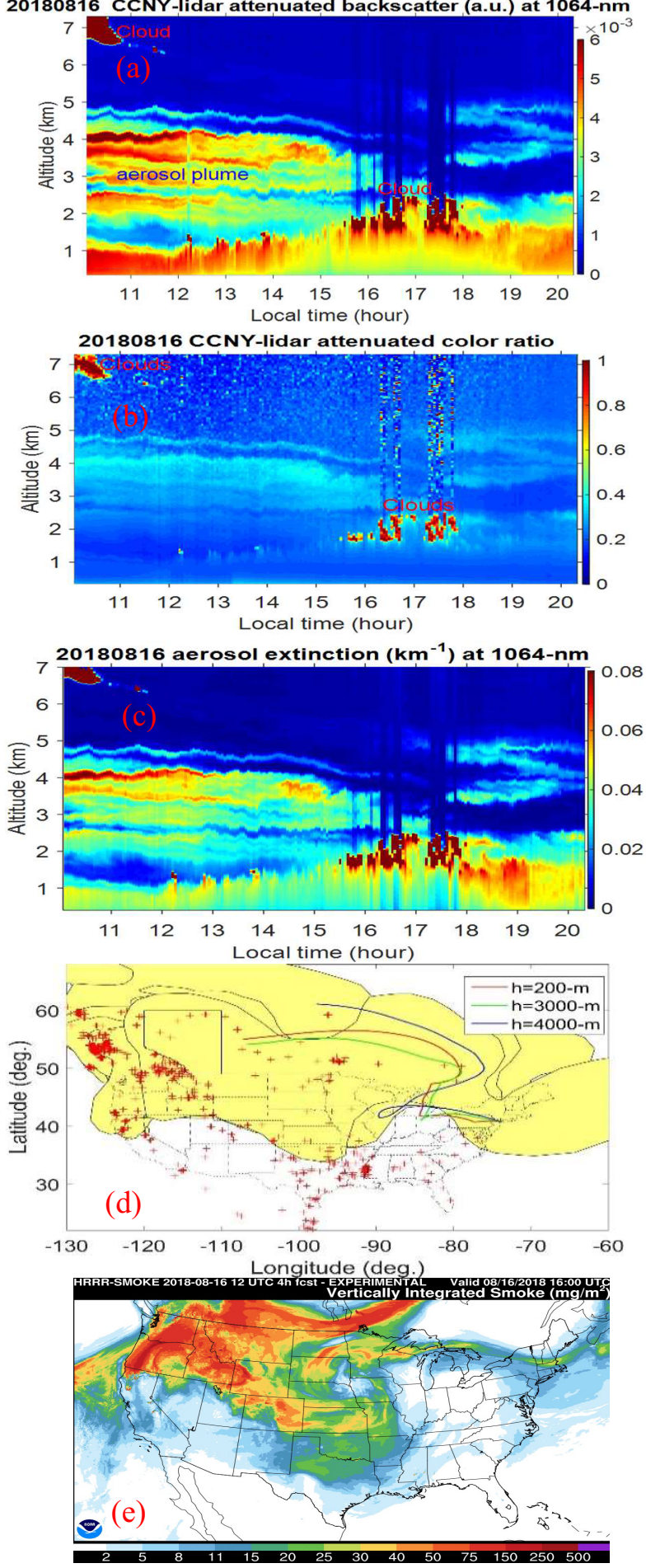

Fig.2 (a)-(c) CCNY-lidar attenuated backscatter, colorratio, aerosol extinction $\left(\mathrm{S}_{1064}=55\right.$-sr $)$, (d)-(e) NOAAHYSPLIT backward trajectory, HMS fire points (red+)smoke (yellow), HRRR model smoke on Aug.16, 2018. 

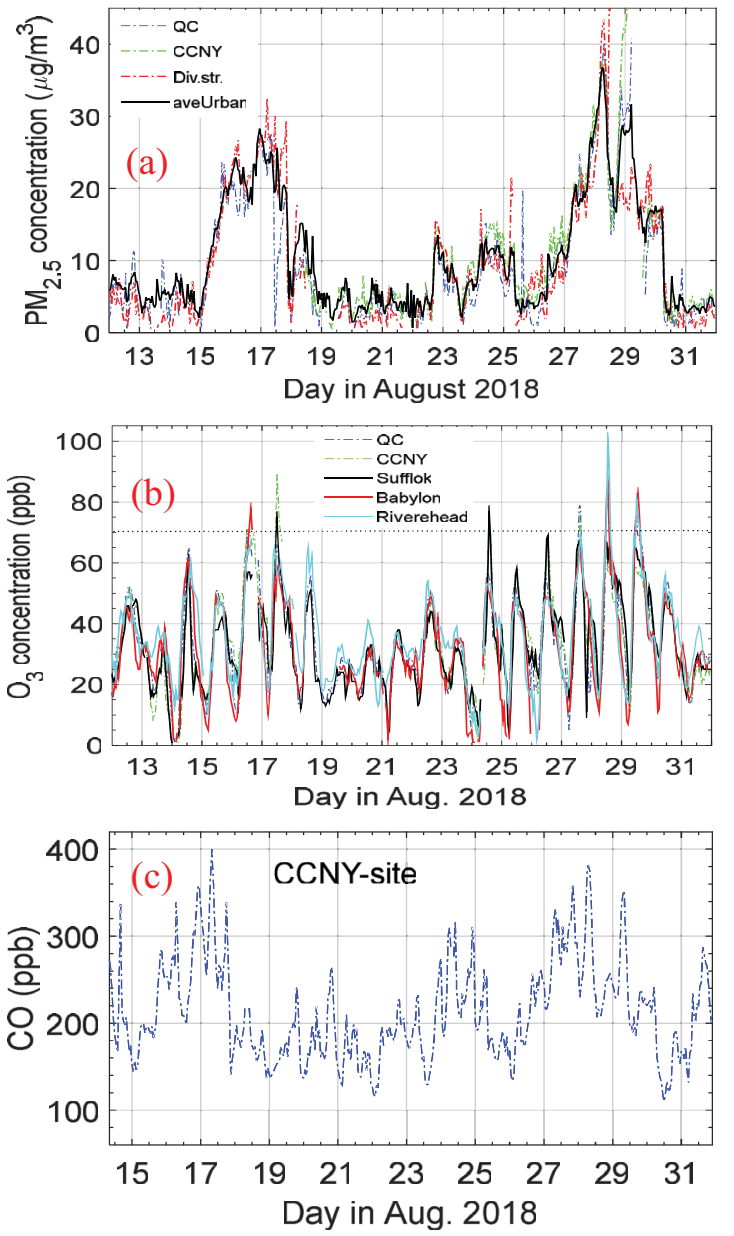

Fig.3 (a)-(c) Ground-level $\mathrm{PM}_{2.5}, \mathrm{O}_{3}$ and $\mathrm{CO}$ variation in NYC during Aug.12-31, 2018.

\subsection{Mixing-layer-height (MLH) variation in the urban, coastal and marine area}

Figure 4 gives the MLH comparison measured by the ceilometer and lidar in the NYC urban, coastal and marine area on Aug. 29, 2018. In Fig.4 (a), the ship-track with the local time in the LIS is given. In the marine and costal area, the mixing-layer shows a low and stable top at $0.3 \mathrm{~km}$ before 11:30, then a consistent increase up to $1.5 \mathrm{~km}$ at 14:00, following with a high top. In contrast, in the urban area as shown in Fig.4(c), the MLHs start to increase at 10:00 am, then reach up to maximum at $\sim 12: 30$, and remains consistently high, in agreement with MLH in the coastal and marine area (Fig.4d). Overall, there is around a 2-hr delay of the MLH morning transition in the coast and marine area in comparison to the urban area, which might be due to different surface temperatures and roughness over the land and water that affect the PBL development. The low MLH in the morning corresponds to high ground $\mathrm{PM}_{2.5}$ in Fig.3 (a). In addition, the PBLHs from the NAM model $(4-\mathrm{km}$ grid) indicate much lower values in the LIS than the ones in the NYC urban area after 14:00 EDT, which is not consistent with the observations.
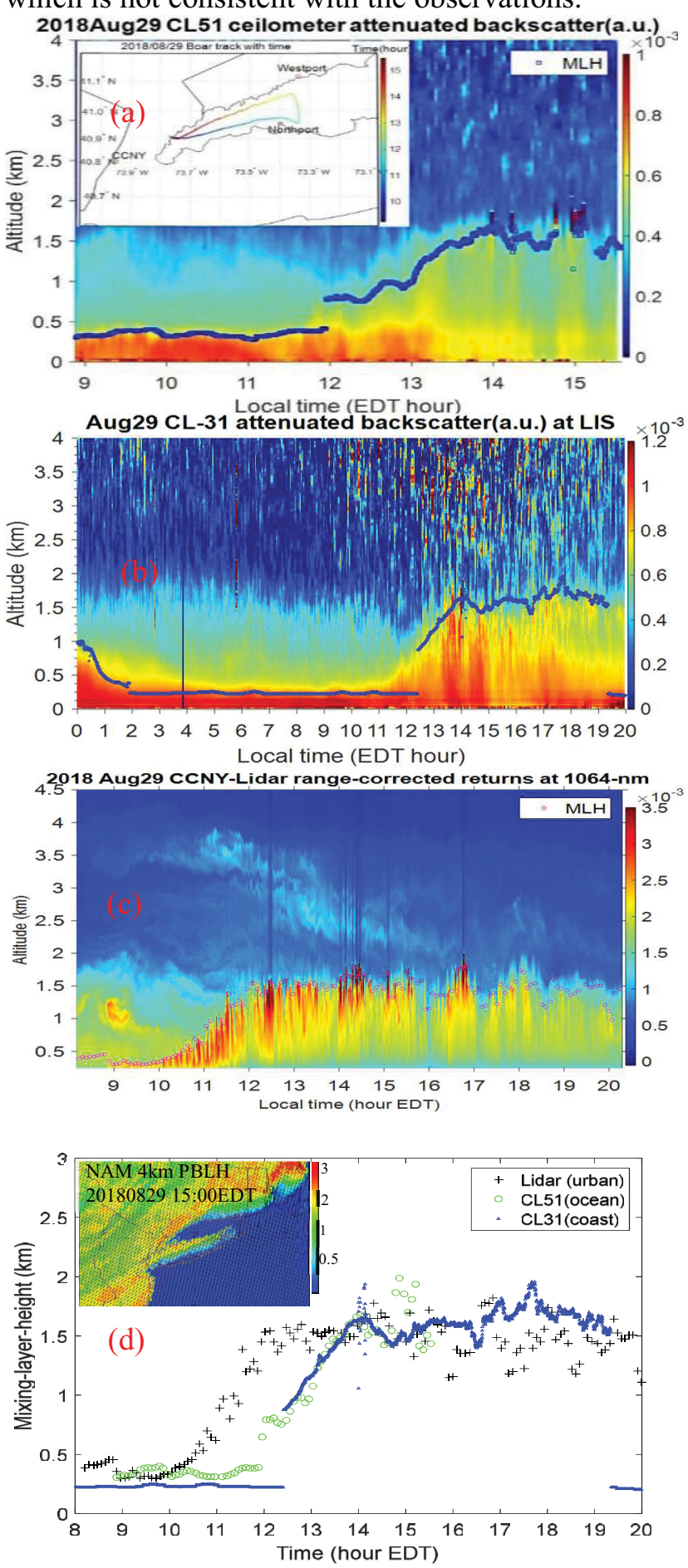

Fig.4(a)-d) Ceilometer/lidar measured attenuated backscatter and MLH in the (a) ocean, (b) coast, (c) urban and (d) their comparison and model MLH in NYC area on Aug. 29, 2018. 


\subsection{Evaluation of model forecast}

Figure 5 gives the comparison of PBLH, ground $\mathrm{PM}_{2.5}$ and $\mathrm{O}_{3}$ between the NAM-CMAQ model and the observations at CCNY-site, respectively. First, Fig.5 (a) indicates consistent diurnal evolution of PBLH, particularly for the convective PBL. But, the model shows an underestimate in the morning and night. On the other hand, the model $\mathrm{PM}_{2.5}$ generally agree with the observations on Aug. 2728, but show large biases on Aug. 29. The model $\mathrm{O}_{3}$ agree with the observation in term of temporal variation and peak values at noon, but are underestimated in the morning and night.
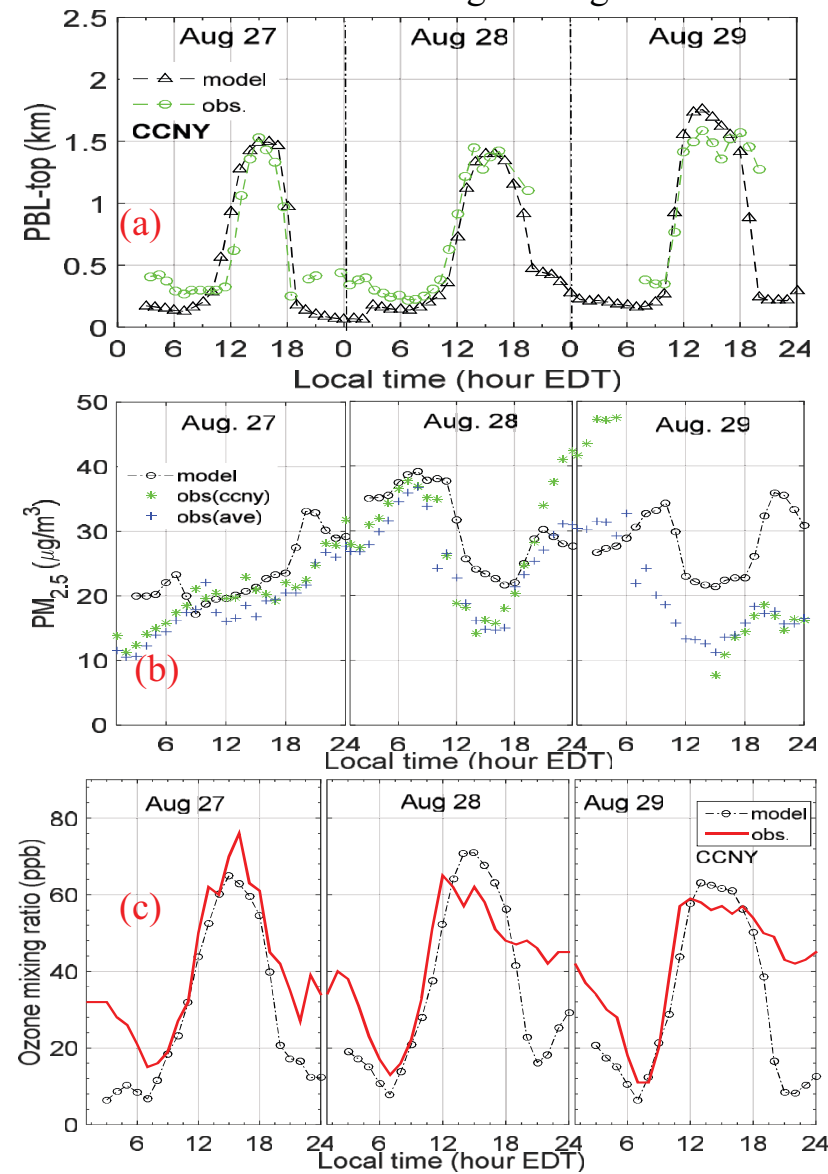

Fig.5 (a)-(c) Comparison of PBLH, $\mathrm{PM}_{2.5}$ and $\mathrm{O}_{3}$ between the NAM-CMAQ model and observation.

\section{CONCLUSION}

This abstract considers a case study and investigation of the wildfire smoke transport and PBLH spatial variation in NYC area in summer 2018. The optical properties of aloft aerosols, mixing into the PBL and potential impacts on air quality are indicated from the lidar and in-situ measurements. The elevated plumes contribute as much as $\sim 70 \%$ to the column AOD whereas the ground $\mathrm{PM}_{2.5}$ and $\mathrm{CO}$ show dramatic increase (e.g. $\mathrm{PM}_{2.5}$ from 5 to $30 \mu \mathrm{g} / \mathrm{m}^{3}$ ) in the NYC area. The sources and transport paths from the northwest US/Canada to the northeast US are verified by the NOAA-HMS, HYSPLIT backward trajectory and HRRR-smoke model. In addition, we present a case study of temporal and spatial variation of MLH in the urban, coastal and marine area. The simultaneous observations by a CCNY-lidar and two ceilometers indicate around 2-hr delay for the morning transit of MLH in the coast and marine area in comparison to the urban area, but consistently high MLH or PBLH from noon to afternoon. The initial comparison of NOAA NAMCMAQ forecast with the observations indicate the consistent diurnal variation of PBLH and $\mathrm{O}_{3}$, but biases in the early morning and night, which may be associated with the vertical mixing process, PBLH and chemical formation.

\section{ACKNOWLEDGEMENTS}

The New York State Energy Research and Development Authority (grant \# 100415 and 137482), NESCAUM (grant \# 2411) and the NOAA-Cooperative Science Center for Earth System Sciences and Remote Sensing Technologies under the Cooperative Agreement Grant \#NA16SEC4810008 support this study. We appreciate the data from NYSDEC, NASA and NOAA-HMS, HYSPLIT and HRRR model.

\section{REFERENCES}

[1] Miller, Paul J., 2017: Retrospective and Future Analysis of Air Quality In and Downwind of New York City, DRAFT White Paper, available at ww.nescaum.org/documents/listos.

[2] Wu, Y., et al., 2018: Intra-continental wildfire smoke transport and impact on local air quality observed by ground-based and satellite remote sensing in New York City, Atmos. Environ., 187, 266-281.

[3] Angevine, W.M., et al., 2004: Coastal Boundary Layer Influence on Pollutant Transport in New England. J. Appl. Meteor., 43, 1425-1437.

[4] Huang, J., et al., 2017: Improving NOAA NAQFC $\mathrm{PM}_{2.5}$ predictions with a bias correction approach, Wea. and Forecasting, 32, 407-421.

[5] Wu, Y., et al., 2009: Low and optically thin cloud measurements using a Raman-Mie lidar, Appl. Opt., 48, 1218-1227.

[6] Holben, B.N., et al., 1998: AERONET A federated instrument network and data archive for aerosol characterization, Rem. Sens. Environ., 66, 1-16.

[7] Rattigan, O. V., et al., 2010: Multi-year hourly $\mathrm{PM}_{2.5}$ carbon measurements in New York: diurnal, day of week and seasonal patterns, Atmos. Environ., 44 (16), 2043-2053. 